\title{
Overall profit Malmquist productivity index under data uncertainty
}

\author{
Dariush Akbarian
}

\section{Correspondence:}

d_akbarian@yahoo.com Department of Mathematics, Arak Branch, Islamic Azad University, Arak, Iran

\begin{abstract}
The calculation of the overall profit Malmquist productivity index (MPI) requires precise and accurate information on the input, output, input-output prices of each decision making unit (DMU). However, in many situations, some inputs and/or outputs and input-output prices are imprecise. As such, we consider the overall profit MPI problem when the input, output, and input-output prices are imprecise and vary over intervals, showing that method (MCM 54: 2827-2838, 2011) has some shortfalls. To remedy these shortfalls, we propose another method for measuring the overall profit MPI when the inputs, outputs, and price vectors vary over intervals. That is, to calculate the overall profit efficiency intervals, cone-ratio data envelopment analysis models can be applied to the incorporated information as weight restrictions. Further, we provide a new approach to calculating the upper bound of the overall profit efficiency of each DMU. A numerical example is provided for illustrating the proposed method.
\end{abstract}

Keywords: Data envelopment analysis, Imprecise data, Profit Malmquist productivity index

\section{Introduction}

The Malmquist productivity index (MPI) is one of the most popular approaches to measuring productivity changes over time and was introduced by Malmquist (1953). Under data envelopment analysis (DEA), productivity is defined as the ratio between efficiency and is measured by MPI for the same decision making unit (DMU) in two different periods. Caves et al. (1982a;1982b) proposed an MPI as the ratio of two input distance functions to calculate the relative performance of a DMU in different periods. Färe et al. (1994) extended the approach of Caves et al. (1982a) and constructed an MPI directly using input and output data as the geometric mean of the MPIs calculated in the two base periods. Using Farrell's (1957) methodology for the measurement of efficiency and that of Caves et al. (1982a) on the measurement of productivity, Färe et al. (1994) constructed an MPI directly from input and output data using DEA. However, this conventional profit MPI requires the input-output quantity and exact input-output prices to be available. However, in many situations, some inputs and/or outputs and input-output prices have imprecise data. Therefore, conventional profit MPI models are not suitable or applicable to measuring overall profit MPI.

Asmild et al. (2007) presented a framework in which DEA was used to measure the overall efficiencies of different behavioral objectives. Furthermore, they showed how this framework could be applied to assess the effectiveness of more general behavioral goals.

(c) The Author(s). 2020 Open Access This article is distributed under the terms of the Creative Commons Attribution 4.0 International License (http://creativecommons.org/licenses/by/4.0/), which permits unrestricted use, distribution, and reproduction in any medium, provided you give appropriate credit to the original author(s) and the source, provide a link to the Creative Commons license, and indicate if changes were made. 
These objectives are revenue maximization, cost minimization, and profit maximization. Asmild et al. (2007) clarified the relationships between various cone-ratio DEA (CRDEA) models and those used to measure overall efficiency. Aghayi et al. () evaluated the MPI of DMUs with desirable and undesirable interval outputs. To deal with data uncertainty, a fuzzy approach was proposed by Wanke et al. (2016), who also calculated the efficiency of banks. Mashayekhi and Omrani (2016) used a fuzzy approach for sorting genetic algorithms with uncertain data. Salehpour and Aghayi (2015) calculated revenue efficiency under price uncertainty to find a solution to minimizing the worst-case performance with uncertain data. Hatami-Marbini et al. (2018) developed an overarching evaluation process for estimating the RTS of DMUs under imprecise DEA (IDEA), where the input and output data lie within bounded intervals. For more on IDEA, see Shabani et al. (2019), Ebrahimi (2018), Fazelabdolabadi (2019), Toloo et al. (2018), Shokouhi et al. (2014), Hatami-Marbini et al. (2017), Ureña et al. (2019), Zhang et al. (2019), Kao et al. (2014) and the references therein.

The MPI computation using DEA with uncertain data has not been studied widely in the literature. For instance, Emrouznejad et al. (2011) studied the overall profit MPI using DEA with fuzzy and interval data. They extended the model (39) of Asmild et al. (2007) and proposed two methods for measuring the overall profit MPI when the input, output, and price vectors are fuzzy or vary over intervals (see Emrouznejad et al. (2011), models (3a) and (3b)). To the best of our knowledge, to compute the overall profit MPI of each DMU, the profit efficiency at time period $t[(t+1)$ must be computed using the technology and input-output prices at time period $t+1$ ] ( $t$ ) (see (Tohidi et al. 2010; Tohidi et al. 2014). However, in Emrouznejad et al's (2011) method, the input-output prices in periods $t$ and $t+1$ are used simultaneously, meaning the results are not reasonable (see subsection 2.2. for details). As such, this paper overcomes the shortfall of Emrouznejad et al's model (3b) (Emrouznejad et al. 2011). Park (2001) introduced an approach to deal with IDEA involving variable input and output. He considered the multiplier and envelopment IDEA models (Cooper et al. 1999; Lee et al. 2002) and clarified the relationships between them. These models yield an upper and a lower bound on efficiency, respectively. Mostafaee and Saljooghi (2010) extended the classical cost efficiency models to include data uncertainty. However, Fang and Li (2012) showed that Mostafaee and Saljooghi's (2010) approach had some drawbacks. Then, Fang and Li (2013) extended Park's approach and presented an alternative IDEA method to calculate an upper and a lower bound of cost efficiency measurement in the presence of imprecise price inputs. Based on the studies of Park (2001) and Emrouznejad et al. (2011), this paper introduces alternative methods for measuring the overall profit MPI when the input, output, and input-output prices are uncertain and also measures the lower and upper bounds of overall profit MPIs. We show that the upper bound of the overall profit efficiency is obtained by incorporating uncertain data as interval data directly into the overall profit efficiency models. In addition, the lower bound of the overall profit efficiency is achieved by incorporating the same uncertain data as weight restrictions into a CR-DEA model. The main contributions of this paper are as follows: (a) we calculate the overall profit MPI assuming that input, output, and input-output prices are imprecise; (b) we characterized these imprecise data with interval methods; (c) we propose models to measure the overall profit efficiency in adjacent periods, which has a reasonable interpretation (see model (4)); (d) we establish new models to compute the 
upper bounds for the profit efficiency measures; (e) we extend the model using CR-DEA; and (f) we demonstrate the practical aspects of our model using a numerical example.

The remainder of this paper is organized as follows. "Overall profit efficiency and MPIs" section presents an overview of overall profit efficiency and Malmquist indices. "Main results" section proposes models to calculate the lower and upper bounds of the profit efficiency of each DMU within the period and for adjusted periods. In "Computational aspects" section, we develop new methods to calculate the upper bounds of the overall profit efficiency of each DMU. A numerical example is also provided in "Computational aspects" section. Finally, "Conclusions" section concludes the paper.

\section{Overall profit efficiency and MPIs}

MPIs measure the productivity change of a DMU between two different time periods. Färe et al. $(1994,1992)$ developed an input based non-parametric Malmquist index using DEA. This DEA-based Malmquist productivity can be extended to measure the productivity changes of DMUs over time. Here, we discuss the overall profit efficiency and overall profit MPIs.

\section{Overall profit efficiency}

Consider a set of $n$ DMUs associated with $m$ inputs and $s$ outputs. Particularly, $D M U_{j}$ $(j \in J=1, \ldots, n)$ consumes amount $x_{i j}$ of input $i$ and produces amount $y_{r j}$ of output $r$. Let $X_{j}=\left(x_{1 j}, \ldots, x_{m j}\right)$, where $X_{j} \geq 0 \& X_{j} \neq 0$ and $Y_{j}=\left(y_{1 j}, \ldots, y_{r j}\right)$ and where $Y_{j} \geq 0 \& Y_{j} \neq 0$. In addition, $c$ and $r$ are the input and output price vectors, respectively, for $D M U_{j}(j \in J=1, \ldots, n)$, where $c \geq 0$ and $r \geq 0, c \neq 0$, and $r \neq 0$. Asmild (2007) presented the following model for measuring the overall profit efficiency of $D M U_{o}=\left(x_{o}, y_{o}\right),(o=1, \ldots, n)$ :

$$
\begin{aligned}
\max & \frac{r_{o}^{T} y}{r_{o}^{T} y_{o}}-\frac{c_{o}^{T} x}{c_{o}^{T} x_{o}} \\
\text { s.t. } & -\sum_{j \in J} \lambda_{j} y_{j}+y \leq 0 \\
& \sum_{j \in J} \lambda_{j} x_{j}-x \leq 0 \\
& \sum_{j \in J} \lambda_{j}=1, \\
& \lambda_{j} \geq 0
\end{aligned}
$$

where $x, y$, and $\lambda_{j}, j \in J$ are variables and the objective function of this linear program is to maximize the difference between the revenue and cost ratios for a given price vector $p_{o}^{T}=\left(c_{o}^{T}, r_{o}^{T}\right)$ for the $D M U_{o}$ under assessment. Superscript $T$ stands for a transposed vector.

The following definition and theorem refer to (Toloo et al. 2008).

Definition $1 D M U_{o}$ is overall profit efficient if in model (1), $\frac{r_{y}^{T} y^{*}}{r_{o}^{T} y_{o}}-\frac{c_{0}^{T} x^{*}}{c_{o}^{T} x_{o}}=0$.

Theorem 1 For every optimal solution $\left(x^{*}, y^{*}, \lambda^{*}\right)$ of $(1)$, we have $\frac{r_{0}^{T} y^{*}}{r_{o}^{T} y_{o}}-\frac{c_{c}^{T} x^{*}}{c_{o}^{T} x_{o}} \geq 0$.

\section{Overall profit MPIs}

Emrouznejad et al. (2011) used the following model to measure the overall profit efficiency in the adjacent period: 


$$
\begin{aligned}
D_{o}^{p}\left(x_{o}^{q}, y_{o}^{q} \mid p, q=t, t+1, p \neq q\right)=\max & \varphi-\theta \\
& \text { s.t. } \quad \varphi\left[\left(r_{j}^{p}\right)^{T} y_{0}^{p}\right] \leq\left(r_{j}^{q}\right)^{T} Y^{q} \lambda, \forall j, \\
& \theta\left[\left(c_{j}^{p}\right)^{T} x_{0}^{p}\right] \leq\left(c_{j}^{q}\right)^{T} X^{q} \lambda, \forall j, \\
& \lambda \geq 0,
\end{aligned}
$$

where $X^{p}$ and $Y^{p}$ are the input and output matrices of the observed data for period $p$, respectively. To the best of our knowledge, to compute the overall profit MPI of $D M U_{o}$, the profit efficiency of $D M U_{o}^{p}=\left(x_{o}^{p}, y_{o}^{p}\right)$ must be computed using the technology and input-output prices at period $q,(p, q=t, t+1, p \neq q)$ (see Tohidi et al. (2010; 2014). However, in (2), the input-output prices in period $p$ and $q$ are used simultaneously. To overcome this shortfall, this paper introduces variable returns to scale overall profit efficiency in the within and adjacent periods as (3) and (4), respectively:

$$
\begin{aligned}
& B_{o}^{p}\left(x_{o}^{p}, y_{o}^{p} \mid p=t, t+1\right)=\max \frac{\left(r_{o}^{p}\right)^{T} y}{\left(r_{o}^{p}\right)^{T} y_{o}^{p}}-\frac{\left(c_{o}^{p}\right)^{T} x}{\left(c_{o}^{p}\right)^{T} x_{o}^{p}} \\
& \text { s.t. } \quad-\sum_{j \in J} \lambda_{j} y_{j}^{p}+y \leq 0 \sum_{j \in J} \lambda_{j} x_{j}^{p}-x \leq 0 \\
& \sum_{j \in J} \lambda_{j}=1, \\
& \lambda \geq 0 \\
& D_{o}^{q}\left(x_{o}^{p}, y_{o}^{p} \mid p, q=t, t+1, p \neq q\right)=\max \quad \frac{\left(r_{o}^{q}\right)^{T} y}{\left(r_{o}^{q}\right)^{T} y_{o}^{p}}-\frac{\left(c_{o}^{q}\right)^{T} x}{\left(c_{o}^{q}\right)^{T} x_{o}^{p}} \\
& \text { s.t. } \quad-\sum_{j \in J} \lambda_{j} y_{j}^{q}+y \leq 0 \\
& \\
& \sum_{j \in J} \lambda_{j} x_{j}^{q}-x \leq 0 \\
& \sum_{j \in J} \lambda_{j}=1, \\
& \lambda \geq 0
\end{aligned}
$$

where $x_{j}^{p}$ and $y_{j}^{p}$ are the input and output of $D M U_{j}$ in period $p$, respectively.

Models (3) and (4) have clear interpretations. Model (3) calculates the profit efficiency of $D M U_{o}^{p}$ using the technology and input-output prices in period $p$ and model (4) calculates the profit efficiency of $D M U_{o}^{p}$ using the technology and input-output prices in period $q,(p, q=t, t+1, p \neq q)$.

The following definitions and theorem refer to (Emrouznejad et al. 2011).

Theorem 2 For every optimal solution $\left(x^{*}, y^{*}, \lambda^{*}\right)$ of (3), we have $\frac{\left(r_{o}^{p}\right)^{T} y^{*}}{\left(r_{o}^{p}\right)^{T} y_{o}^{p}}-\frac{\left(c_{o}^{p}\right)^{T} x^{*}}{\left(c_{o}^{p}\right)^{T} x_{o}^{p}} \geq 0$.

Proof Model (3) has a feasible solution $\lambda_{o}=1, \lambda_{j}=0, j \neq o$. Hence, the optimal objective, denoted by $\frac{\left(r_{o}^{p}\right)^{T} y^{*}}{\left(r_{o}^{p}\right)^{T} y_{o}^{p}}-\frac{\left(c_{o}^{p}\right)^{T} x^{*}}{\left(c_{o}^{p}\right)^{T} x_{o}^{p}}$, is greater than or equal to 0, i.e., $\frac{\left(r_{o}^{p}\right)^{T} y^{*}}{\left(r_{o}^{p}\right)^{T} y_{o}^{p}}-\frac{\left(c_{o}^{p}\right)^{T} x^{*}}{\left(c_{o}^{p}\right)^{T} x_{o}^{p}} \geq$ 0 .

Remarks 1 The objective function values for model (4) can be less than or equal to zero.

Definition $2 D M U_{o}$ is overall efficient if $D_{o}^{t+1}\left(x_{o}^{t+1}, y_{o}^{t+1}\right)=0$ and $D_{o}^{t}\left(x_{o}^{t}, y_{o}^{t}\right)=0$.

Definition 3 The efficiency scores of models (3) and (4) are respectively computed as follows: 
(i) If $\frac{\left(r_{o}^{p}\right)^{T} y^{*}}{\left(r_{o}^{p}\right)^{T} y_{o}^{p}}-\frac{\left(c_{o}^{p}\right)^{T} x^{*}}{\left(c_{o}^{p}\right)^{T} x_{o}^{p}} \geq 0$, then $\rho=\frac{1}{1+\frac{\left(r_{o}^{p}\right)^{T} y^{*}}{\left(r_{o}^{p}\right)^{T} y_{o}^{p}}-\frac{\left(c_{o}^{p}\right)^{T} x^{*}}{\left(c_{o}^{p}\right)^{T} x_{o}^{p}}}$.

(ii) If $\frac{\left(r_{r^{q}}^{q}\right)^{T} y^{*}}{\left(r_{o}^{q}\right)^{T} y_{o}^{p}}-\frac{\left(c_{o}^{q}\right)^{T} x^{*}}{\left(c_{o}^{q}\right)^{T} x_{o}^{p}} \leq 0$, then $\rho=1+\frac{\left(r_{o}^{q}\right)^{T} y^{*}}{\left(r_{o}^{q}\right)^{T} y_{o}^{p}}-\frac{\left(c_{o}^{q}\right)^{T} x^{*}}{\left(c_{o}^{q}\right)^{T} x_{o}^{p}}$.

Obviously, if $\rho=1 D M U_{o}$ is efficient and if $\rho<1, D M U_{o}$ is inefficient.

Definition 4 The overall profit MPI of $D M U_{o}$ is defined as follows:

$$
M_{o}=\sqrt{\frac{\rho_{o}^{t}\left(x_{o}^{t+1}, y_{o}^{t+1}\right)}{\rho_{o}^{t}\left(x_{o}^{t}, y_{o}^{t}\right)} \times \frac{\rho_{o}^{t+1}\left(x_{o}^{t+1}, y_{o}^{t+1}\right)}{\rho_{o}^{t+1}\left(x_{o}^{t}, y_{o}^{t}\right)}} .
$$

Therefore, the following three conditions hold:

(i) $M_{o}>1$, increase productivity and observe progress;

(ii) $M_{o}<1$, decrease productivity and observe regress; and

(iii) $M_{o}=1$, no change in productivity at time $t+1$ compared to $t$.

\section{Main results}

Here, we consider the overall profit efficiency and overall profit MPI of $D M U_{o}, o=1, \ldots, n$ when input, output, and input-output prices are uncertain and also define an interval for the overall profit MPI of $D M U_{o}$. We reiterate that there are $n$ DMUs under consideration.

Assume that $\left[x_{i j}^{p L}, x_{i j}^{p U}\right]$ and $\left[y_{k j}^{p L}, y_{k j}^{p U}\right]$ are the intervals of input $i$ and output $k$ of $D M U_{j}$, $(j \in J)$ in period $p$, respectively. Additionally, $\left[c_{i o}^{p L}, c_{i o}^{p U}\right]$, and $\left[r_{k o}^{p L}, r_{k o}^{p U}\right]$ are the intervals of the input-output prices of input $i$ and output $k$ of $D M U_{o}, o=1, \ldots, n$ in period $p$, respectively. Models (3) and (4) can be extended to the overall profit efficiency models (5) and (6) with data uncertainty, respectively:

$$
\begin{aligned}
& \text { Within - period time } \\
& B_{o}^{p}\left(x_{o}^{p}, y_{o}^{p} \mid p=t, t+1\right)=\max \frac{\left(r_{o}^{p}\right)^{T} y}{\left(r_{o}^{p}\right)^{T} y_{o}^{p}}-\frac{\left(c_{o}^{p}\right)^{T} x}{\left(c_{o}^{p}\right)^{T} x_{o}^{p}} \\
& \text { s.t. } \quad-\sum_{j \in J} \lambda_{j} y_{j}^{p}+y \leq 0 \\
& \sum_{j \in J} \lambda_{j} x_{j}^{p}-x \leq 0 \\
& \sum_{j \in J} \lambda_{j}=1 \\
& c_{i o}^{p} \in\left[c_{i o}^{p L}, c_{i o}^{p U}\right], \quad i=1, \ldots, m \\
& r_{k o}^{p} \in\left[r_{k o}^{p L}, r_{k o}^{p U}\right], \quad k=1, \ldots, s \\
& x_{i j}^{p} \in\left[x_{i j}^{p L}, x_{i j}^{p U}\right], \quad i=1, \ldots, m \\
& y_{k j}^{p} \in\left[y_{k j}^{p L}, y_{k j}^{p U}\right], \quad k=1, \ldots, s \\
& \lambda_{j} \geq 0, \quad j \in J \text {. }
\end{aligned}
$$


Adjacent-period time

$$
\begin{aligned}
& D_{o}^{q}\left(x_{o}^{p}, y_{o}^{p} \mid p, q=t, t+1, p \neq q\right)=\max \frac{\left(r_{o}^{q}\right)^{T} y}{\left(r_{o}^{q}\right)^{T} y_{o}^{p}}-\frac{\left(c_{o}^{q}\right)^{T} x}{\left(c_{o}^{q}\right)^{T} x_{o}^{p}} \\
& \text { s.t. } \quad-\sum_{j \in J} \lambda_{j} y_{j}^{q}+y \leq 0 \\
& \sum_{j \in J} \lambda_{j} x_{j}^{q}-x \leq 0 \\
& \sum_{j \in J} \lambda_{j}=1 \\
& c_{i o}^{q} \in\left[c_{i o}^{q L}, c_{i o}^{q U}\right], \quad i=1, \ldots, m \\
& r_{k o}^{q} \in\left[r_{k o}^{q L}, r_{k o}^{q U}\right], \quad k=1, \ldots, s \\
& x_{i j}^{q} \in\left[x_{i j}^{q L}, x_{i j}^{q U}\right], \quad i=1, \ldots, m \\
& y_{k j}^{q} \in\left[y_{k j}^{q L}, y_{k j}^{q U}\right], \quad k=1, \ldots, s \\
& x_{i o}^{p} \in\left[x_{i o}^{p L}, x_{i o}^{p U}\right], \quad i=1, \ldots, m \\
& y_{k o}^{p} \in\left[y_{k o}^{p L}, y_{k o}^{p U}\right], \quad k=1, \ldots, s . \\
& \lambda_{j} \geq 0, \quad j \in J
\end{aligned}
$$

It can be observed that models (5) and (6) are nonlinear programming programs because of data uncertainty.

Of particular importance is how to solve the newly constructed profit efficiency models with data uncertainty in (5) and (6). To illustrate these issues, we introduce the following definitions, which are similar to those of Park (2001).

Definition 5 (Potential profit efficiency in the within-period time) The DMU $U_{o}$ to be evaluated is potentially profit efficient in the within-period if and only if there exists at least one set of prices $c_{o}^{p} \in\left[c_{o}^{p L}, c_{o}^{p U}\right]$ and $r_{o}^{p} \in\left[r_{o}^{p L}, r_{o}^{p U}\right]$ and at least one set of input-output data satisfying $x_{i j}^{p} \in\left[x_{i j}^{p L}, x_{i j}^{p U}\right]$ and $y_{k j}^{p} \in\left[y_{k j}^{p L}, y_{k j}^{p U}\right](j \in J)$, so that $B_{o}^{p *}=0^{1}$ in model (5).

Definition 6 (Perfect profit efficiency in the within-period time) The DMU $U_{o}$ to be evaluated is perfectly profit efficient in the within-period if and only if, for all $c_{o}^{p} \in\left[c_{o}^{p L}, c_{o}^{p U}\right]$ and $r_{o}^{p} \in\left[r_{o}^{p L}, r_{o}^{p U}\right]$ and all input-output data, $x_{i j}^{p} \in\left[x_{i j}^{p L}, x_{i j}^{p U}\right]$ and $y_{k j}^{p} \in\left[y_{k j}^{p L}, y_{k j}^{p U}\right](j \in J)$, $B_{o}^{p *}=0$ are satisfied in model (5).

Definition 7 (Potential profit efficiency in the adjacent period) The DMU $U_{o}$ to be evaluated is potentially profit efficient in the adjacent period if and only if there exists at least one set of prices $c_{o}^{q} \in\left[c_{o}^{q L}, c_{o}^{q U}\right]$ and $r_{o}^{q} \in\left[r_{o}^{q L}, r_{o}^{q U}\right]$ and at least one set of inputoutput data satisfying $x_{i j}^{q} \in\left[x_{i j}^{q L}, x_{i j}^{q U}\right], y_{k j}^{q} \in\left[y_{k j}^{q L}, y_{k j}^{q U}\right](j \in J), x_{i o}^{p} \in\left[x_{i o}^{p L}, x_{i o}^{p U}\right]$ and $y_{k o}^{p} \in\left[y_{k o}^{p L}, y_{k o}^{p U}\right](p, q=t, t+1, p \neq q)$, so that $D_{o}^{q *}=0$ in model (6).

Definition 8 (Perfect profit efficiency in the adjacent period) The $D M U_{o}$ to be evaluated is perfectly profit efficient in the adjacent-period time if and only if, for all $c_{o}^{q} \in\left[c_{o}^{q L}, c_{o}^{q U}\right]$ and $r_{o}^{q} \in\left[r_{o}^{q L}, r_{o}^{q U}\right]$ and all input-output data, $x_{i j}^{q} \in\left[x_{i j}^{q L}, x_{i j}^{q U}\right], y_{k j}^{q} \in\left[y_{k j}^{q L}, y_{k j}^{q U}\right](j \in J)$, $x_{i o}^{p} \in\left[x_{i o}^{p L}, x_{i o}^{p U}\right]$ and $y_{k o}^{p} \in\left[y_{k o}^{p L}, y_{k o}^{p U}\right](p, q=t, t+1, p \neq q)$ are satisfied so that $D_{o}^{q *}=0$ in model (6). 
In definitions 5 and 7, the profit efficiency of $D M U_{o}$ is measured for some data, while definitions 6 and 8 refer to the profit efficiency of $D M U_{o}$ for all data. Therefore, perfect profit efficiency is measured in a more rigid manner than potential profit efficiency. In the spirit of Park (2001), we can represent these definitions using the following mathematical formulations, where term UPEW-S (UPEW-P) refers to the uncertain profit efficiency of $D M U_{o}^{p}=\left(x_{o}^{p}, y_{o}^{p}\right)$ with the technology and prices at time $p$, the within period, for some (for perfect (all)). Additionally, term UPEA-S (UPEA-P) refers to uncertain profit efficiency of $D M U_{o}^{p}=\left(x_{o}^{p}, y_{o}^{p}\right)$ with technology and prices at time $q$, the adjacent period, for some (for perfect (all)) $(p, q=t, t+1, p \neq q)$ :

The UPEW-S model:

$$
\bar{B}_{o}^{p}\left(x_{o}^{p}, y_{o}^{p} \mid p=t, t+1\right)=\max \quad \begin{gathered}
\frac{\left(r_{o}^{p}\right)^{T} y}{\left(r_{o}^{p}\right)^{T} y_{o}^{p}}-\frac{\left(c_{o}^{p}\right)^{T} x}{\left(c_{o}^{p}\right)^{T} x_{o}^{p}} \\
\text { s.t. } \quad \sum_{j \in J} \lambda_{j} y_{j}^{p}+y \leq 0 \\
\sum_{j \in J} \lambda_{j} x_{j}^{p}-x \leq 0 \\
\sum_{j \in J} \lambda_{j}=1 \\
\text { for some }\left\{c_{i o}^{p} \in\left[c_{i o}^{p L}, c_{i o}^{p U}\right], i=1, \ldots, m\right\} \\
\text { for some }\left\{r_{k o}^{p} \in\left[r_{k o}^{p L}, r_{k o}^{p U}\right], k=1, \ldots, s\right\} \\
\text { for some }\left\{x_{i j}^{p} \in\left[x_{i j}^{p L}, x_{i j}^{p U}\right], i=1, \ldots, m\right\} \\
\text { for some }\left\{y_{k j}^{p} \in\left[y_{k j}^{p L}, y_{k j}^{p U}\right], k=1, \ldots, s\right\} \\
\lambda_{j} \geq 0 .
\end{gathered}
$$

The UPEW-P model:

Model (7) with $\underline{B}_{o}^{p}$ in place of $\bar{B}_{o}^{p}$ and "for all"

in place of "for some."

The UPEA-S model:

$$
\begin{aligned}
& \bar{D}_{o}^{q}\left(x_{o}^{p}, y_{o}^{p} \mid p, q=t, t+1, p \neq q\right)=\max \\
& \frac{\left(r_{o}^{q}\right)^{T} y}{\left(r_{o}^{q}\right)^{T} y_{o}^{p}}-\frac{\left(c_{q}^{q}\right)^{T} x}{\left(c_{o}^{q}\right)^{T} x_{o}^{p}} \\
& \text { s.t. } \\
& -\sum_{j \in J} \lambda_{j} y_{j}^{q}+y \leq 0 \\
& \sum_{j \in J} \lambda_{j} x_{j}^{q}-x \leq 0 \\
& \sum_{j \in J} \lambda_{j}=1 \\
& \text { for some }\left\{c_{i o}^{q} \in\left[c_{i o}^{q L}, c_{i o}^{q U}\right], \quad i=1, \ldots, m\right\} \\
& \text { for some }\left\{r_{k o}^{q} \in\left[r_{k o}^{q L}, r_{k o}^{q U}\right], \quad k=1, \ldots, s\right\} \\
& \text { for some }\left\{x_{i j}^{q} \in\left[x_{i j}^{q L}, x_{i j}^{q U}\right], \quad i=1, \ldots, m\right\} \\
& \text { for some }\left\{y_{k j}^{q} \in\left[y_{k j}^{q L}, y_{k j}^{q L}\right], \quad k=1, \ldots, s\right\}
\end{aligned}
$$

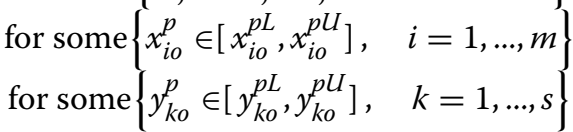

$$
\begin{aligned}
& \lambda_{j} \geq 0 \text {. }
\end{aligned}
$$

The UPEA-P model:

Model (9) with $\underline{D}_{o}^{q}$ in place of $\bar{D}_{o}^{q}$ and "for all"

in place of "for some." 
Clearly, $\bar{B}_{o}^{p} \geq \underline{B}_{o}^{p}\left(\bar{D}_{o}^{q} \geq \underline{D}_{o}^{q}\right)$ because the feasible region of model (8) (10) is always contained within the feasible region of model (7) (9).

Using models (7) and (8), we can obtain the interval of profit efficiency of $D M U_{o}$ in the within-period as $\left[\underline{B}_{o}^{p}, \bar{B}_{o}^{p}\right]$. Additionally, by models (9) and (10), the interval of profit efficiency of $D M U_{o}$ in the adjacent period can be obtained as $\left[\underline{D}_{o}^{q}, \bar{D}_{o}^{q}\right] . \underline{B}_{o}^{p}\left(\underline{D}_{o}^{q}\right)$ is the lower bound of the interval overall profit efficiency of $D M U_{o}$ from the pessimistic viewpoint in the within period (adjacent period) and $\bar{B}_{o}^{p}\left(\bar{D}_{o}^{q}\right)$ is the upper bound of the interval overall profit efficiency of $D M U_{o}$ from the optimistic viewpoint in the within period (adjacent period).

Remarks 2 It is clear that model (5) is equivalent to the UPEW-S model (7) and model (6) is equivalent to the UPEA-S model (9).

Because of the notion of maximization "for some" and "for all" in the permissible data, the UPEW-S (7), UPEW-P (8), UPEA-S (9), and UPEA-P models (10) are equivalent to the two-level mathematical programs (11), (12), (13), and (14), respectively:

$$
\begin{array}{ll}
\bar{B}_{o}^{p}=\max \quad \max & \frac{\left(r_{o}^{p}\right)^{T} y}{\left(r_{o}^{p}\right)^{T} y_{o}^{p}}-\frac{\left(c_{o}^{p}\right)^{T} x}{\left(c_{o}^{p}\right)^{T} x_{o}^{p}} \\
c_{i o}^{p} \in\left[c_{i o}^{p L}, c_{i o}^{p U}\right] \\
r_{k o}^{p} \in\left[r_{k o}^{p L}, r_{k o}^{p U}\right] \\
x_{i j}^{p} \in\left[x_{i j}^{p L}, x_{i j}^{p U}\right] \\
y_{k j}^{p} \in\left[y_{k j}^{p L}, y_{k j}^{p U}\right] \\
\text { s.t. } & -\sum_{j \in J} \lambda_{j} y_{j}^{p}+y \leq 0 \\
& \sum_{j \in J} \lambda_{j j} x_{j}^{p}-x \leq 0 \\
& \sum_{j \in J} \lambda_{j}=1 \\
& \lambda_{j} \geq 0 .
\end{array}
$$

Model (11) but with " $\underline{B}_{o}^{p}=\min$ " in place of " $\bar{B}_{o}^{p}=\max$ ".

$$
\begin{array}{ll}
\bar{D}_{o}^{p}=\max \quad \max & \frac{\left(r_{o}^{q}\right)^{T} y}{\left(r_{o}^{q}\right)^{T} y_{o}^{p}}-\frac{\left(c_{o}^{q}\right)^{T} x}{\left(c_{o}^{q}\right)^{T} x_{o}^{p}} \\
c_{i o}^{q} \in\left[c_{i o}^{q L}, c_{i o}^{q U}\right] \\
r_{k o}^{q} \in\left[r_{k o}^{q L}, r_{k o}^{q U}\right] \\
x_{i j}^{q} \in\left[x_{i j}^{q L}, x_{i j}^{q U}\right] \\
y_{k j}^{q} \in\left[y_{k j}^{q L}, y_{k j}^{q U}\right] \\
x_{i o}^{p} \in\left[x_{i o}^{p L}, x_{i o}^{p U}\right] \\
y_{k o}^{p} \in\left[y_{k o}^{p L}, y_{k o}^{p U}\right] \\
\\
\quad \text { s.t. } & -\sum_{j \in J} \lambda_{j} y_{j}^{q}+y \leq 0 \\
& \sum_{j \in J} \lambda_{j} x_{j}^{q}-x \leq 0 \\
& \sum_{j \in J} \lambda_{j}=1 \\
& \lambda_{j} \geq 0 .
\end{array}
$$

Model (13) but with " $\underline{D}_{o}^{p}=\min$ " in place of " $\bar{D}_{o}^{p}=\max$ ". 
In model (11), the inner program calculates the overall profit efficiency for each given set of $\left(x_{o}^{p}, y_{o}^{p}\right)$ for a price vector $\left(r_{o}^{p}, c_{o}^{p}\right)$ defined in the outer program, using the technology of period $p$, while the outer program determines the set of $\left(x_{o}^{p}, y_{o}^{p}\right)$ and price vector $\left(r_{o}^{p}, c_{o}^{p}\right)$ that generate the highest overall profit efficiency. Additionally, in model (13), the inner program calculates the overall profit efficiency for each given set of $\left(x_{o}^{p}, y_{o}^{p}\right)$ for a given price vector $\left(r_{o}^{q}, c_{o}^{q}\right)$ using the technology of period $q(p, q=t, t+1, p \neq q)$, defined in the outer program, while the outer program determines the set of $\left(x_{o}^{p}, y_{o}^{p}\right)$ and price vector $\left(r_{o}^{q}, c_{o}^{q}\right)$ that generate the highest overall profit efficiency. A similar explanation can be provided for models (12) and (14).

By duality, models (11)-(14) are equivalent to the following models:

$$
\begin{aligned}
& \bar{B}_{o}^{p}=\max \quad \min \mu_{o} \\
& c_{i o}^{p} \in\left[c_{i o}^{p L}, c_{i o}^{p U}\right] \\
& r_{k o}^{p} \in\left[r_{k o}^{p L}, r_{k o}^{p U}\right] \\
& x_{i j}^{p} \in\left[x_{i j}^{p L}, x_{i j}^{p U^{\prime}}\right. \\
& y_{k j}^{p} \in\left[y_{k j}^{p L}, y_{k j}^{p U}\right]
\end{aligned}
$$

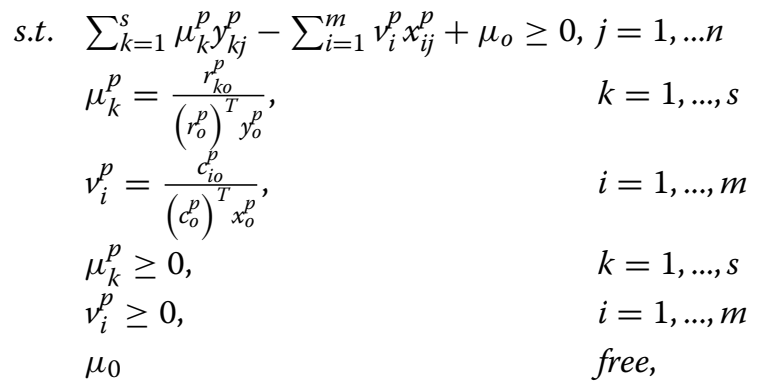

Model (15) but with " $\underline{B}_{o}^{p}=\min$ " in place of " $\bar{B}_{o}^{p}=\max$ ".

$$
\begin{aligned}
& \bar{D}_{o}^{p}=\max \quad \min \mu_{o} \\
& c_{i o}^{q} \in\left[c_{i o}^{q L}, c_{i o}^{q U}\right] \\
& r_{k o}^{q} \in\left[r_{k o}^{q L}, r_{k o}^{q U}\right. \\
& x_{i j}^{q} \in\left[x_{i j}^{q L}, x_{i j}^{q U}\right. \\
& y_{k j}^{q} \in\left[y_{k j}^{q L}, y_{k j}^{q U}\right. \\
& x_{i o}^{p} \in\left[x_{i o}^{p L}, x_{i o}^{p U}\right] \\
& y_{k o}^{p} \in\left[y_{k o}^{p L}, y_{k o}^{p U}\right] \\
& \text { s.t. } \quad \sum_{k=1}^{s} \mu_{k}^{q} y_{k j}^{q}-\sum_{i=1}^{m} v_{i}^{q} x_{i j}^{q}+\mu_{o} \geq 0, j=1, \ldots n \\
& \mu_{k}^{q}=\frac{r_{k o}^{q}}{\left(r_{o}^{q}\right)^{T} y_{o}^{p}}, \quad k=1, \ldots, s \\
& v_{i}^{q}=\frac{c_{i o}^{q}}{\left(c_{c}^{q}\right)^{T} x_{o}^{p}}, \quad i=1, \ldots, m \\
& \mu_{k}^{q} \geq 0, \quad k=1, \ldots, s \\
& v_{i}^{q} \geq 0, \quad i=1, \ldots, m \\
& \mu_{0} \quad \text { free. }
\end{aligned}
$$

Model (17) but with " $\underline{D}_{o}^{p}=\min$ " in place of " $\bar{D}_{o}^{p}=\max$ ".

First, we proceed to models (16) and (18). Their inner and outer programs have the same objective of minimization. Therefore, they can be combined into a one-level model 
by considering all constraints of the two programs simultaneously. The one-level models equivalent to (16) and (18) are (19) and (20), respectively:

$$
\begin{aligned}
& \underline{B}_{o}^{p}=\min \mu_{o} \\
& \text { s.t. } \sum_{k=1}^{s} \mu_{k}^{p} y_{k j}^{p}-\sum_{i=1}^{m} v_{i}^{p} x_{i j}^{p}+\mu_{o} \geq 0, j=1, \ldots n \\
& \mu_{k}^{p}=\frac{r_{k o}^{p}}{\left(r_{o}^{p}\right)^{T} y_{o}^{p}}, \quad k=1, \ldots, s \\
& v_{i}^{p}=\frac{c_{i o}^{p}}{\left(c_{o}^{p}\right)^{T} x_{o}^{p}}, \quad i=1, \ldots, m \\
& c_{i o}^{p} \in\left[c_{i o}^{p L}, c_{i o}^{p U}\right] \\
& r_{k o}^{p} \in\left[r_{k o}^{p L}, r_{k o}^{p U}\right] \\
& x_{i j}^{p} \in\left[x_{i j}^{p L}, x_{i j}^{p U}\right] \\
& y_{k j}^{p} \in\left[y_{k j}^{p L}, y_{k j}^{p U}\right] \\
& \mu_{k}^{p} \geq 0 \text {, } \\
& v_{i}^{p} \geq 0 \text {, } \\
& \mu_{0} \quad \text { free } \\
& \lambda_{j} \geq 0 \text {, } \\
& \underline{D}_{o}^{p}=\min \mu_{o}
\end{aligned}
$$

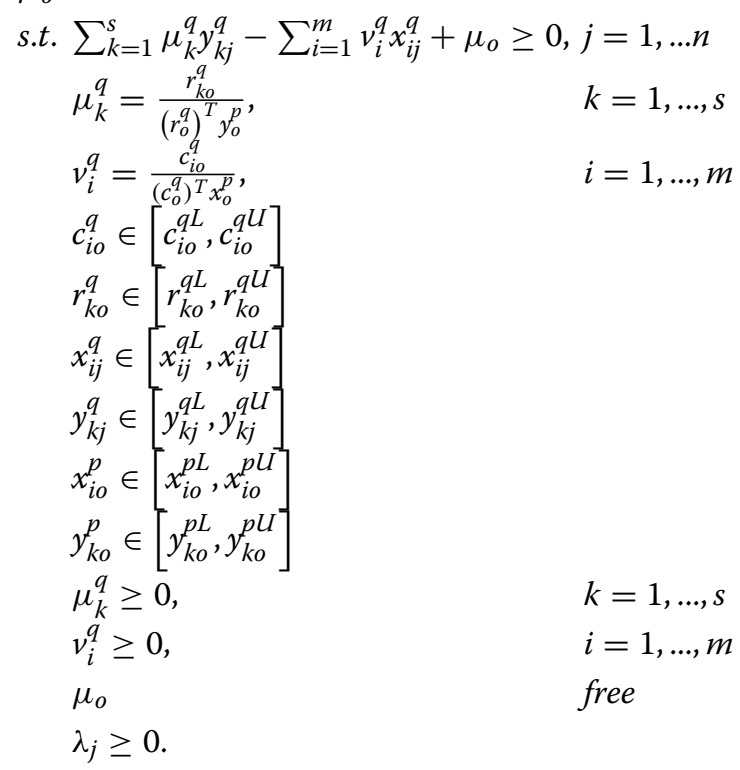

Evidently the above models (19) and (20) are nonlinear programming problems and thus difficult to solve. To linearize model (19), we introduce variables $z^{p}$ and $\tau^{p}$, defined by:

$$
\begin{aligned}
& z^{p}=\frac{1}{\left(c_{o}^{p}\right)^{T} x_{o}^{p}}, \\
& \tau^{p}=\frac{1}{\left(r_{o}^{p}\right)^{T} y_{o}^{p}}, \\
& \text { so that } \\
& v_{i}^{p}=c_{i o}^{p} z^{p} \Longleftrightarrow c_{i o}^{p L} z^{p} \leq v_{i}^{p} \leq c_{i o}^{p U} z^{p}, \\
& \mu_{k}^{p}=r_{k o}^{p} \tau^{p} \Longleftrightarrow r_{k o}^{p L} \tau^{p} \leq \mu_{k}^{p} \leq r_{k o}^{p U} \tau^{p}, \\
& \sum_{k=1}^{s} r_{k o}^{p} \tau^{p} y_{k o}^{p}=1 \Longleftrightarrow \sum_{k=1}^{s} \mu_{k}^{p} y_{k o}^{p}=1, \\
& \sum_{i=1}^{m} c_{i o}^{p} z^{p} x_{i o}^{p}=1 \Longleftrightarrow \sum_{i=1}^{m} v_{i}^{p} x_{i o}^{p}=1 .
\end{aligned}
$$

Similarly, to the linearization of model (20), we introduce variables $z^{q}$ and $\tau^{q}$, defined by: 


$$
\begin{aligned}
& z^{q}=\frac{1}{\left(c_{o}^{q}\right)^{T} x_{o}^{p}}, \\
& \tau^{q}=\frac{1}{\left(r_{o}^{q}\right)^{T} y_{o}^{p}}, \\
& \text { so that } \\
& v_{i}^{q}=c_{i o}^{q} z^{q} \Longleftrightarrow c_{i o}^{q L} z^{q} \leq v_{i}^{q} \leq c_{i o}^{q u} z^{q}, \\
& \mu_{k}^{q}=r_{k o}^{q} \tau^{q} \Longleftrightarrow r_{k o}^{q L} \tau^{q} \leq \mu_{k}^{q} \leq r_{k o}^{q U} \tau^{q}, \\
& \sum_{k=1}^{s} r_{k}^{q} \tau^{q} y_{k o}^{p}=1 \Longleftrightarrow \sum_{k=1}^{s} \mu_{k}^{q} y_{k o}^{p}=1, \\
& \sum_{i=1}^{m} c_{i o}^{q} z^{q} x_{i o}^{p}=1 \Longleftrightarrow \sum_{i=1}^{m} v_{i}^{q} x_{i o}^{p}=1, \\
& \text { where } p, q=t, t+1, p \neq q .
\end{aligned}
$$

Using the above variable alterations, models (19) and (20) can be converted into the following programming problems, whose optimal objective values coincide with those of (19) and (20), respectively:

$$
\begin{aligned}
& \underline{B}_{o}^{p}=\min \mu_{o} \\
& \text { s.t. } \sum_{k=1}^{s} \mu_{k}^{p} y_{k j}^{p}-\sum_{i=1}^{m} v_{i}^{p} x_{i j}^{p}+\mu_{o} \geq 0, j=1, \ldots n \\
& \sum_{k=1}^{s} \mu_{k}^{p} y_{k o}^{p}=1 \\
& \sum_{i=1}^{m} v_{i}^{p} x_{i o}^{p}=1 \\
& c_{i o}^{p L} z^{p} \leq v_{i}^{p} \leq c_{i o}^{p U} z^{p} \\
& r_{k o}^{p L} \tau^{p} \leq \mu_{k}^{p} \leq r_{k o}^{p U} \tau^{p} \\
& x_{i j}^{p} \in\left[x_{i j}^{p L}, x_{i j}^{p U}\right] \\
& y_{k j}^{p} \in\left[y_{k j}^{p L}, y_{k j}^{p U}\right] \\
& z^{p} \geq 0 \\
& \tau^{p} \geq 0 \\
& \mu_{k}^{p} \geq 0, \\
& v_{i}^{p} \geq 0 \text {, } \\
& \mu_{0} \\
& k=1, \ldots, s \\
& i=1, \ldots, m \\
& \lambda_{j} \geq 0 \text {, } \\
& \underline{D}_{o}^{p}=\min \mu_{o} \\
& \begin{array}{ll}
\text { s.t. } & \sum_{k=1}^{s} \mu_{k}^{q} y_{k j}^{q}-\sum_{i=1}^{m} v_{i}^{q} x_{i j}^{q}+\mu_{o} \geq 0, j=1, \ldots n \\
& \sum_{k=1}^{s} \mu_{k}^{q} y_{k o}^{p}=1 \\
& \sum_{i=1}^{m} v_{i}^{q} x_{i o}^{p}=1 \\
c_{i o}^{q L} z^{q} \leq v_{i}^{q} \leq c_{i o}^{q u} z^{q} & \\
r_{k o}^{q L} \tau^{q} \leq \mu_{k}^{q} \leq r_{k o}^{q U} \tau^{q} & \\
x_{i j}^{q} \in\left[x_{i j}^{q L}, x_{i j}^{q U}\right. & \\
y_{k j}^{q} \in\left[y_{k j}^{q L}, y_{k j}^{q U}\right] & \\
x_{i o}^{p} \in\left[x_{i o}^{p L}, x_{i o}^{p U}\right] \\
y_{k o}^{p} \in\left[y_{k o}^{p L}, y_{k o}^{p U}\right] \\
z^{q} \geq 0 & \\
\tau^{q} \geq 0 & \\
\mu_{k}^{q} \geq 0, & \\
v_{i}^{q} \geq 0, & \\
\mu_{o} & \\
\lambda_{j} \geq 0 . & \text { free } \\
&
\end{array} \\
& \text { free }
\end{aligned}
$$

Similar to Lemma (1) of (Podinovski 2001), we propose the following Lemma, which refers to the general weight bound problem: 
Lemma 1 Imposing the absolute bounds of $c_{i o}^{p L} z^{p} \leq v_{i}^{p} \leq c_{i o}^{p U} z^{p},\left(i=1, \ldots, m, z^{p} \geq 0\right)$ and $r_{k o}^{p L} \tau^{p} \leq \mu_{k}^{p} \leq r_{k o}^{p U} \tau^{p},\left(k=1, \ldots, s, \tau^{p} \geq 0\right)$ is equivalent to imposing bounds on the ratios of the weights of the following form:

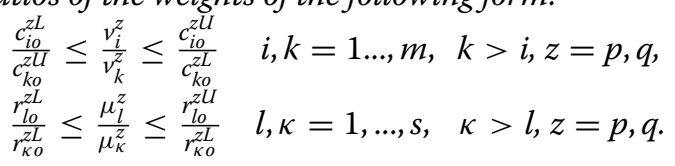

Let $y_{k j}=\alpha_{k} y_{k j}^{U}+\left(1-\alpha_{k}\right) y_{k j}^{L}$ and $x_{i j}=\beta_{i} x_{i j}^{U}+\left(1-\beta_{i}\right) x_{i j}^{L}$ for some $\alpha_{k} \in[0,1]$ and $\beta_{i} \in[0,1]$. It is easy to show that the first three constraints of models (21) and (22) can be written as (23) and (24), respectively:

$$
\begin{aligned}
& \sum_{k=1}^{s} \gamma_{k}\left(y_{k j}^{U p}-y_{k j}^{L p}\right)+\sum_{k=1}^{s} \mu_{k}^{p} y_{k j}^{L p}-\sum_{i=1}^{m} v_{i}^{p} x_{i j}^{L p}-\sum_{i=1}^{m} \omega_{i}\left(x_{i j}^{U p}-x_{i j}^{L p}\right)+\mu_{o} \geq 0, \quad j=1, \ldots n \\
& \sum_{k=1}^{s} \gamma_{k}\left(y_{k o}^{U p}-y_{k o}^{L p}\right)+\sum_{k=1}^{s} \mu_{k}^{p} y_{k o}^{L p}=1 \\
& \sum_{i=1}^{m} \omega_{i}\left(x_{i o}^{U p}-x_{i o}^{L p}\right)+\sum_{i=1}^{m} v_{i}^{p} x_{i o}^{L p}=1,
\end{aligned}
$$

$$
\begin{aligned}
& \sum_{k=1}^{s} \gamma_{k}\left(y_{k j}^{U q}-y_{k j}^{L q}\right)+\sum_{k=1}^{s} \mu_{k}^{q} y_{k j}^{L q}-\sum_{i=1}^{m} v_{i}^{q} x_{i j}^{L q}-\sum_{i=1}^{m} \omega_{i}\left(x_{i j}^{U q}-x_{i j}^{L q}\right)+\mu_{o} \geq 0, \quad j=1, \ldots n \\
& \sum_{k=1}^{s} \gamma_{k}\left(y_{k o}^{U p}-y_{k o}^{L p}\right)+\sum_{k=1}^{s} \mu_{k}^{q} y_{k o}^{L p}=1 \\
& \sum_{i=1}^{m} \omega_{i}\left(x_{i o}^{U p}-x_{i o}^{L p}\right)+\sum_{i=1}^{m} v_{i}^{q} x_{i o}^{L o}=1,
\end{aligned}
$$

where $\gamma_{k}=\mu_{k} \alpha_{k}$ and $\omega_{i}=v_{i} \beta_{i}$ for each $i$ and $k$.

By applying Lemma 1 and constraints (23) and (24) to models (21) and (22), we obtain the equivalent linear formulations of models (21) and (22), called the CR-DEA models, as follows:

$$
\begin{aligned}
& \underline{B}_{o}^{p}=\min \mu_{o} \\
& \text { s.t. } \quad \sum_{k=1}^{s} \gamma_{k}\left(y_{k j}^{U p}-y_{k j}^{L p}\right)+\sum_{k=1}^{s} \mu_{k}^{p} y_{k j}^{L p}-\sum_{i=1}^{m} v_{i}^{p} x_{i j}^{L p}-\sum_{i=1}^{m} \omega_{i}\left(x_{i j}^{U p}-x_{i j}^{L p}\right)+\mu_{o} \geq 0, \quad j=1, \ldots n \\
& \sum_{k=1}^{s} \gamma_{k}\left(y_{k o}^{U p}-y_{k o}^{L p}\right)+\sum_{k=1}^{s} \mu_{k}^{p} y_{k o}^{L p}=1 \\
& \sum_{i=1}^{m} \omega_{i}\left(x_{i o}^{U p}-x_{i o}^{L p}\right)+\sum_{i=1}^{m} v_{i}^{p} x_{i o}^{L p}=1 \\
& \frac{c_{i o}^{p L}}{c_{k o}^{p U}} \leq \frac{v_{i}^{p}}{v_{k}^{p}} \leq \frac{c_{i o}^{p U}}{c_{k o}^{p L}} \\
& \frac{r_{l o}^{p L}}{r_{\kappa o}^{p L}} \leq \frac{\mu_{l}^{p}}{\mu_{\kappa}^{p}} \leq \frac{r_{l o}^{p U}}{r_{\kappa o}^{p L}}, \quad l, \kappa=1, \ldots, s, \kappa>l
\end{aligned}
$$


$0 \leq \gamma_{k} \leq \mu_{k}^{p}$

$0 \leq \omega_{i} \leq v_{i}^{p}$

$\mu_{k}^{p} \geq 0$,

$k=1, \ldots, s$

$v_{i}^{p} \geq 0$,

$i=1, \ldots, m$

$\mu_{0}$, free

$\underline{D}_{o}^{p}=\min \mu_{o}$

$$
\begin{aligned}
& \text { s.t. } \sum_{k=1}^{s} \gamma_{k}\left(y_{k j}^{U q}-y_{k j}^{L q}\right)+\sum_{k=1}^{s} \mu_{k}^{q} y_{k j}^{L q}-\sum_{i=1}^{m} v_{i}^{q} x_{i j}^{L q}-\sum_{i=1}^{m} \omega_{i}\left(x_{i j}^{U q}-x_{i j}^{L q}\right)+\mu_{o} \geq 0, \quad j=1, \ldots n \\
& \sum_{k=1}^{s} \gamma_{k}\left(y_{k o}^{U p}-y_{k o}^{L p}\right)+\sum_{k=1}^{s} \mu_{k}^{q} y_{k o}^{L p}=1 \\
& \sum_{i=1}^{m} \omega_{i}\left(x_{i o}^{L p}-x_{i o}^{L p}\right)+\sum_{i=1}^{m} v_{i}^{q} x_{i o}^{L p}=1 \\
& \frac{c_{i o}^{q L}}{c_{k o}^{q U}} \leq \frac{v_{i}^{q}}{v_{k}^{q}} \leq \frac{c_{i o}^{q U}}{c_{k o}^{q L}} \\
& \frac{r_{l o}^{q L}}{r_{\kappa o}^{q L}} \leq \frac{\mu_{l}^{q}}{\mu_{\kappa}^{q}} \leq \frac{r_{l o}^{q U}}{r_{\kappa o}^{q L}} \\
& i, k=1 \ldots, m, k>i \\
& 0 \leq \gamma_{k} \leq \mu_{k}^{q} \\
& 0 \leq \omega_{i} \leq v_{i}^{q} \\
& \mu_{k}^{q} \geq 0, \\
& k=1, \ldots, s \\
& v_{i}^{q} \geq 0 \text {, } \\
& i=1, \ldots, m
\end{aligned}
$$

$\mu_{o}, \quad$ free.

Now, we proceed to models (15) and (17). By applying the mentioned variable alterations to (15) and (17), we have:

$$
\begin{aligned}
& \bar{B}_{o}^{p}=\max \quad \min \mu_{o} \\
& \frac{v_{i}^{p}}{v_{k}^{p}} \in\left[\frac{c_{i o}^{p L}}{c_{k o}^{p U}}, \frac{c_{i o}^{p U}}{c_{k o}^{p L}}\right] \\
& \frac{\mu_{l}^{p}}{\mu_{\kappa}^{p}} \in\left[\frac{r_{l o}^{p L}}{r_{\kappa o}^{p L}}, \frac{r_{l o}^{p l}}{r_{\kappa o}^{p L}}\right] \\
& x_{i j}^{p} \in\left[x_{i j}^{p L}, x_{i j}^{p U}\right. \\
& y_{k j}^{p} \in\left[y_{k j}^{p L}, y_{k j}^{p U}\right] \\
& \text { s.t. } \quad \sum_{k=1}^{s} \mu_{k}^{p} y_{k j}^{p}-\sum_{i=1}^{m} v_{i}^{p} x_{i j}^{p}+\mu_{o} \geq 0, j=1, \ldots n \\
& \sum_{k=1}^{s} \mu_{k}^{p} y_{k o}^{p}=1 \\
& \sum_{i=1}^{m} v_{i}^{p} x_{i o}^{p}=1 \\
& \mu_{k}^{p} \geq 0 \text {, } \\
& v_{i}^{p} \geq 0, \\
& k=1, \ldots, s \\
& \mu_{0} \\
& i=1, \ldots, m \\
& \text { free, }
\end{aligned}
$$




$$
\begin{aligned}
& \bar{D}_{o}^{p}=\max \quad \min \mu_{o} \\
& \frac{\mu_{l}^{q}}{\mu_{\kappa}^{q}} \in\left[\frac{r_{l o}^{q L}}{r_{k q}^{p L}}, \frac{r_{l o}^{q U}}{r_{k Q}^{q L}}\right] \\
& \frac{\mu_{l}^{q}}{\mu_{\kappa}^{q}} \in\left[\frac{r_{l o}^{q L}}{r_{\kappa o}^{q L}}, \frac{r_{l o}^{q} Q}{r_{\kappa Q}^{q L}}\right] \\
& x_{i j}^{q} \in\left[x_{i j}^{q L}, x_{i j}^{q q Q}\right] \\
& y_{k j}^{q} \in\left[y_{k j}^{q L}, y_{k j}^{q U}\right] \\
& x_{i o}^{p} \in\left[x_{i o}^{p L}, x_{i o}^{p U}\right] \\
& y_{k o}^{p} \in\left[y_{k o}^{p L}, y_{k o}^{p U}\right] \\
& \text { s.t. } \quad \sum_{k=1}^{s} \mu_{k}^{q} y_{k j}^{q}-\sum_{i=1}^{m} v_{i}^{q} x_{i j}^{q}+\mu_{o} \geq 0, \quad j=1, \ldots n \\
& \sum_{k=1}^{s} \mu_{k}^{q} y_{k o}^{p}=1 \\
& \sum_{i=1}^{m} v_{i}^{q} x_{i o}^{p}=1 \\
& \mu_{k}^{q} \geq 0, \quad k=1, \ldots, s \\
& v_{i}^{q} \geq 0, \quad i=1, \ldots, m \\
& \mu_{0} \\
& \text { free. }
\end{aligned}
$$

Models (27) and (28) are two-level models. Several authors have proposed methods for solving two-level programs (see, e.g., (Bialas and Karwan 1984; Vicente and Calamai 1994)). However, due to the special structure of models (27) and (28), we introduce another solution in "Computational aspects" section.

We summarize the facts in the above propositions as follows:

1. If we enclose uncertain data into the profit efficiency model (3) as within-period model (5), this model measures the upper bound on the profit efficiency of $D M U_{o}$ in time periods $t$ and $t+1$. If we enclose the same uncertain data into the CR-DEA DEA model in the form of weight restrictions as model (25), this model measures the lower bound on the profit efficiency of $D M U_{o}$ in time periods $t$ and $t+1$.

2. If we enclose uncertain data into the profit efficiency model (4) as adjacent-period model (6), this model measures the upper bound on the profit efficiency of $D M U_{o}$ at time $t(t+1)$ relative to the frontier at time $t+1(t)$. If we enclose uncertain data into the CR-DEA DEA model in the form of weight restrictions as model (26), this model measures the lower bound on the profit efficiency of $D M U_{o}$ at time $t$ $(t+1)$ relative to the frontier at time $t+1(t)$.

3. Profit efficiency model (5), model UPEW-S (7), and two-level model (27) yield the same profit efficiency as potential profit efficiency or the upper bound of profit efficiency in the within period. Model (5) incorporates uncertain data directly into the envelopment model. Model (7) measures the same profit efficiency for the most optimistic viewpoint. A similar argument can be put forward for models (6), (9), and (28).

4. UPEW-P model (8), two-level model (12), and CR-DEA model (25) yield the same efficiency as perfect efficiency or the lower bound of the profit efficiency of $D M U_{o}$ 
at time periods $t$ and $t+1$ (in the within period). Model (8) calculates the same profit efficiency of $D M U_{o}$ from the pessimistic viewpoint. A similar argument can be put forward for model UPEA-P (10), two-level model (14), and CR-DEA model (26) (in the adjacent period).

Definition 9 The lower and upper bounds of the overall profit MPIs are obtained as follows:

$$
\begin{aligned}
& \bar{M}=\sqrt{\frac{\bar{\rho}_{t}^{t+1}}{\underline{\rho}_{t}^{t}} \times \frac{\bar{\rho}_{t+1}^{t+1}}{\underline{\rho}_{t+1}^{t}}}, \\
& \underline{M}=\sqrt{\frac{\underline{\rho}_{t}^{t+1}}{\bar{\rho}_{t}^{t}} \times \frac{\rho_{t+1}^{t+1}}{\bar{\rho}_{t+1}^{t}}}, \text { where } \bar{\rho}_{p}^{p}\left(\underline{\rho}_{p}^{p}\right), p=t, t+1 \text { represents the optimistic (pessimistic) } \\
& \text { efficiency in the within period and is computed by model (7)(8) and definition 3. Addition- } \\
& \text { ally, } \bar{\rho} q\left(\underline{\rho}_{q}^{p}\right), p, q=t, t+1, p \neq q \text { represents the optimistic (pessimistic) efficiency in the } \\
& \text { adjacent-period time, and is computed by model (9)(10) and definition 3. }
\end{aligned}
$$

Theorem 3 Any $\underline{M} \leq M \leq \bar{M}$ can be considered as the overall profit $M P I$ for $D M U_{0}$.

Proof See (Emrouznejad et al. 2011).

Emrouznejad et al. (2011) divided the overall MPI of any $D M U_{o}$ into six classes, as follows:

- No change in productivity class. This class includes all the DMUs with constant productivity, that is, $E_{o}=\left\{D M U_{j}: \underline{M}_{j}=\bar{M}_{j}=1\right\}$.

- Fully increasing productivity class. This class includes all the DMUs with increasing productivity and observed progress under the pessimistic viewpoint, that is, $E^{++}=\left\{D M U_{j}: 1<\underline{M}_{j} \leq \bar{M}_{j}\right\}$.

- Fully decreasing productivity class. This class includes all the DMUs with decreasing productivity and observed regress under the optimistic viewpoint, that is, $E^{--}=\left\{D M U_{j}: \underline{M}_{j} \leq \bar{M}_{j}<1\right\}$.

- Partially increasing productivity class. This class includes all the DMUs with increasing productivity under the optimistic viewpoint and no change in productivity under the pessimistic viewpoint, that is, $E^{+}=\left\{D M U_{j}: \underline{M}_{j}=1, \bar{M}_{j}>1\right\}$.

- Partially decreasing productivity class. This class includes all the DMUs with decreasing productivity under the pessimistic viewpoint and no change in productivity under the optimistic viewpoint, that is, $E^{-}=\left\{D M U_{j}: \underline{M}_{j}<1, \bar{M}_{j}=1\right\}$.

- Partially increasing-decreasing productivity class. This class includes all the DMUs with increasing productivity under the optimistic viewpoint and decreasing productivity under the pessimistic viewpoint, that is, $E=\left\{D M U_{j}: \underline{M}_{j}<1<\bar{M}_{j}\right\}$.

\section{Computational aspects}

As mentioned in the previous section, we can use CR-DEA models (25) and (26) to obtain the lower bounds of the overall profit efficiency of $D M U_{o}$ from the pessimistic viewpoint in the within $\left(\underline{B}_{o}^{p}\right)$ and adjacent periods $\left(\underline{D}_{o}^{q}\right)$, respectively. Regarding the upper bounds, models (27) and (28) are nonlinear two-level programs and cannot be converted to linear one-level programs. Therefore, we propose new methods to achieve the upper bounds as follows. We define $\theta(\nu, \mu)=$ 
$\min \left\{\mu_{o} \mid \mu_{o} \geq \sum_{i=1}^{m} v_{i}^{p} x_{i j}^{p}-\sum_{k=1}^{s} \mu_{k}^{p} y_{k j}^{p}, v_{i}^{p}, \mu_{k}^{p} \geq 0\right\}$. It can be shown that $\theta(v, \mu)$ is piecewise linear, piecewise continuous, and a convex function. Moreover, the feasible spaces of (27) and (28) are bounded. As such, models (27) and (28) have bounded optimal solutions that occur on boundary of the feasible spaces. Therefore, we have the following propositions:

Proposition 1 The optimal objective value of (27) is equal to:

$$
\max \left\{\sum_{k=1}^{s} \gamma(j)_{k}^{*}\left(y_{k j}^{U p}-y_{k j}^{L p}\right)+\sum_{k=1}^{s} \mu(j)_{k}^{p *} y_{k j}^{L p}-\sum_{i=1}^{m} v(j)_{i}^{p *} x_{i j}^{L p}-\sum_{i=1}^{m} \omega(j)_{i}^{*}\left(x_{i j}^{U p}-x_{i j}^{L p}\right), j=1, \ldots, n\right\},
$$

where $\left(\gamma(j)^{*}, v(j)^{p *}, \mu(j)^{p *}, \omega(j)^{*}\right)(j=1, \ldots, n)$ are the optimal solutions of the following linear model:

$$
\begin{aligned}
\max & \left\{\sum_{k=1}^{s} \gamma_{k}\left(y_{k j}^{U p}-y_{k j}^{L p}\right)+\sum_{k=1}^{s} \mu_{k}^{p} y_{k j}^{L p}-\sum_{i=1}^{m} v_{i}^{p} x_{i j}^{L p}-\sum_{i=1}^{m} \omega_{i}\left(x_{i j}^{U p}-x_{i j}^{L p}\right)\right\}, \quad j=1, \ldots, n \\
\text { s.t. } & \sum_{k=1}^{s} \gamma_{k}\left(y_{k o}^{U p}-y_{k o}^{L p}\right)+\sum_{k=1}^{s} \mu_{k}^{p} y_{k o}^{L p}=1 \\
& \sum_{i=1}^{m} \omega_{i}\left(x_{i o}^{U p}-x_{i o}^{L p}\right)+\sum_{i=1}^{m} v_{i}^{p} x_{i o}^{L p}=1 \\
& \frac{c_{i o}^{p L}}{c_{k o}^{p U}} v_{k}^{p} \leq v_{i}^{p} \leq \frac{c_{i o}^{p U}}{c_{k o}^{p L}} v_{k}^{p} \quad i, k=1 \ldots, m, k>i \\
& \frac{r_{l o}^{p L}}{r_{\kappa o}^{p U}} \mu_{\kappa}^{p} \leq \mu_{l}^{p} \leq \frac{r_{l o}^{p U}}{r_{\kappa o}^{p L}} \mu_{\kappa}^{p} \quad l, \kappa=1, \ldots, s, \kappa>l \\
& 0 \leq \gamma_{k} \leq \mu_{k}^{p} \\
& 0 \leq \omega_{i} \leq v_{i}^{p} \\
& \mu_{k}^{p} \geq 0, \quad k=1, \ldots, s \\
& v_{i}^{p} \geq 0, \quad i=1, \ldots, m .
\end{aligned}
$$

Proposition 2 The optimal objective value of (28) is equal to:

$$
\max \left\{\sum_{k=1}^{s} \gamma(j)_{k}^{*}\left(y_{k j}^{U q}-y_{k j}^{L q}\right)+\sum_{k=1}^{s} \mu(j)_{k}^{q *} y_{k j}^{L q}-\sum_{i=1}^{m} v(j)_{i}^{q *} x_{i j}^{L q}-\sum_{i=1}^{m} \omega(j)_{i}^{*}\left(x_{i j}^{U q}-x_{i j}^{L q}\right), j=1, \ldots, n\right\},
$$

where $\left(\gamma(j)^{*}, v(j)^{q *}, \mu(j)^{q *}, \omega(j)^{*}\right)(j=1, \ldots, n)$ are the optimal solutions of the following linear model:

$$
\max \left\{\sum_{k=1}^{s} \gamma_{k}\left(y_{k j}^{U q}-y_{k j}^{L q}\right)+\sum_{k=1}^{s} \mu_{k}^{q} y_{k j}^{L q}-\sum_{i=1}^{m} v_{i}^{q} x_{i j}^{L q}-\sum_{i=1}^{m} \omega_{i}\left(x_{i j}^{U q}-x_{i j}^{L q}\right)\right\}, \quad j=1, \ldots n
$$


Table 1 Input and output data for the five DMUs in Example 1 at times $t$ and $t+1$. Extracted from Emrouznejad et al. (2011)

\begin{tabular}{|c|c|c|c|c|c|c|c|c|}
\hline \multirow[t]{2}{*}{$D M U_{j}$} & \multicolumn{2}{|l|}{$x_{1 j}$} & \multicolumn{2}{|l|}{$x_{2 j}$} & \multicolumn{2}{|l|}{$y_{1 j}$} & \multicolumn{2}{|l|}{$y_{2 j}$} \\
\hline & $t$ & $t+1$ & $t$ & $t+1$ & $t$ & $t+1$ & $t$ & $t+1$ \\
\hline 1 & $(12,15)$ & $(10,14)$ & $(0.21,0.48)$ & $(0.32,0.5)$ & $(138,144)$ & $(130,140)$ & $(21,22)$ & $(20,23)$ \\
\hline 2 & $(10,17)$ & $(11,15)$ & $(0.1,0.7)$ & $(0.21,0.4)$ & $(143,159)$ & $(137,150)$ & $(28,35)$ & $(24,30)$ \\
\hline 3 & $(4,5)$ & $(3,7)$ & $(0.16,0.35)$ & $(0.22,0.42)$ & $(157,198)$ & $(146,160)$ & $(21,29)$ & $(20,30)$ \\
\hline 4 & $(19,22)$ & $(14,23)$ & $(0.12,0.19)$ & $(0.31,0.39)$ & $(158,181)$ & $(159,170)$ & $(21,25)$ & $(25,32)$ \\
\hline 5 & $(14,15)$ & $(17,18)$ & $(0.06,0.09)$ & $(0.1,0.17)$ & $(157,180)$ & $(160,189)$ & $(28,40)$ & $(18,35)$ \\
\hline
\end{tabular}

$$
\begin{aligned}
& \text { s.t. } \sum_{k=1}^{s} \gamma_{k}\left(y_{k o}^{U p}-y_{k o}^{L p}\right)+\sum_{k=1}^{s} \mu_{k}^{q} y_{k o}^{L p}=1 \\
& \sum_{i=1}^{m} \omega_{i}\left(x_{i o}^{L p}-x_{i o}^{L p}\right)+\sum_{i=1}^{m} v_{i}^{q} x_{i o}^{L p}=1 \\
& \frac{c_{i o}^{q L}}{c_{k o}^{q U}} v_{k}^{q} \leq v_{i}^{q} \leq \frac{c_{i o}^{q U}}{c_{k o}^{q L}} v_{k}^{q} \quad i, k=1 \ldots, m, k>i \\
& \frac{r_{l o}^{q L}}{r_{\kappa o}^{q u}} \mu_{\kappa}^{q} \leq \mu_{l}^{q} \leq \frac{r_{l o}^{q U}}{r_{\kappa o}^{q L}} \mu_{\kappa}^{q} \quad l, \kappa=1, \ldots, s, \kappa>l \\
& 0 \leq \gamma_{k} \leq \mu_{k}^{q} \\
& 0 \leq \omega_{i} \leq v_{i}^{q} \\
& \mu_{k}^{q} \geq 0, \quad k=1, \ldots, s \\
& v_{i}^{q} \geq 0, \quad i=1, \ldots, m \\
& \mu_{0} \quad \text { free. }
\end{aligned}
$$

In model (30) (32) we maximize the linear objective functions individually and then

\begin{tabular}{|c|c|c|c|c|c|c|c|c|}
\hline \multirow[t]{2}{*}{$D M U_{j}$} & \multicolumn{2}{|l|}{$\left(\underline{r}_{1 j}, \bar{r}_{1 j}\right)$} & \multicolumn{2}{|l|}{$\left(\underline{r}_{2 j}, \bar{r}_{2 j}\right)$} & \multicolumn{2}{|l|}{$\left(\underline{c}_{1 j}, \bar{c}_{1 j}\right)$} & \multicolumn{2}{|l|}{$\left(\underline{c}_{2 j}, \bar{c}_{2 j}\right)$} \\
\hline & $t$ & $t+1$ & $t$ & $t+1$ & $t$ & $t+1$ & $t$ & $t+1$ \\
\hline 1 & {$[10,12]$} & {$[11,15]$} & {$[30,35]$} & {$[23,30]$} & {$[100,110]$} & {$[110,115]$} & {$[50,55]$} & {$[40,50]$} \\
\hline 2 & {$[9,10]$} & {$[8,9]$} & {$[27,28]$} & {$[24,29]$} & {$[110,115]$} & {$[114,117]$} & {$[40,44]$} & {$[42,45]$} \\
\hline 3 & {$[8,9]$} & {$[5,9]$} & {$[25,27]$} & {$[25,26]$} & {$[105,110]$} & {$[102,109]$} & {$[42,45]$} & {$[42,50]$} \\
\hline 4 & {$[9,11]$} & {$[7,12]$} & {$[29,31]$} & {$[23,26]$} & {$[107,115]$} & {$[114,115]$} & {$[50,57]$} & {$[49,52]$} \\
\hline 5 & {$[10,11]$} & {$[10,14]$} & {$[28,31]$} & {$[24,30]$} & {$[111,117]$} & {$[110,114]$} & {$[47,62]$} & {$[42,52]$} \\
\hline
\end{tabular}
calculate the highest using (29) (31).

Example. We consider five DMUs with two inputs and two outputs, as per Table 1. Table 2 shows the interval price vectors at time $t$ and $t+1$. Using models (25) and (30), the interval of profit efficiency for $D M U_{o}$ in the within period is $\left[\underline{B}_{o}^{p}, \bar{B}_{o}^{p}\right]$ and using models (26) and (32) the interval of profit efficiency for $D M U_{o}$ in the adjacent period time is $\left[\underline{D}_{o}^{q}, \bar{D}_{o}^{q}\right]$. The overall profit MPIs are shown in Table 3. As per Table $3, D M U_{4}$ is classified in the fully increasing productivity class, which is the

Table 2 Numerical example 1

The price vector data for the five DMUs in Example 1 at times $t$ and $t+1$ 


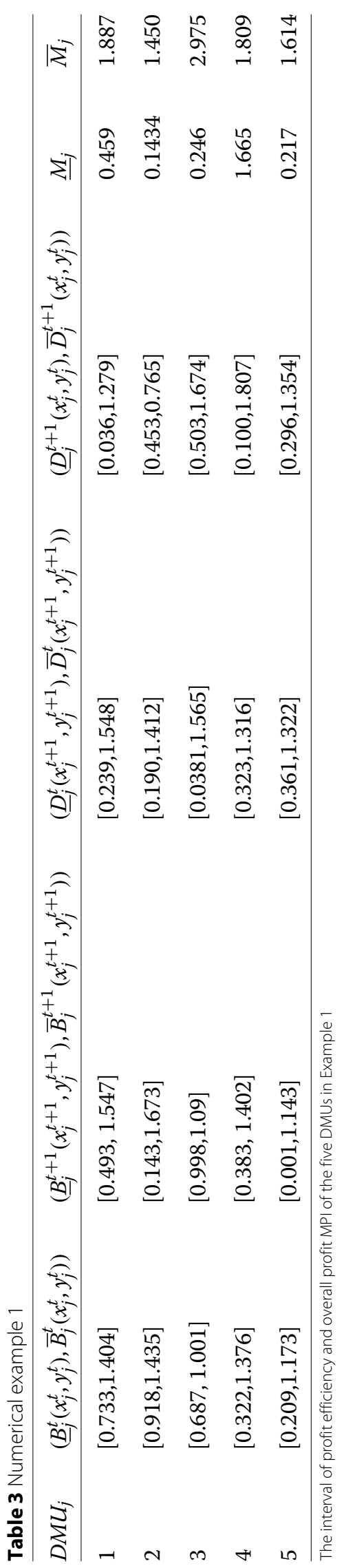


observed progress under the pessimistic viewpoint. Other DMUs are classified in the partially increasing-decreasing productivity class and they thus have increasing productivity under the optimistic viewpoint and decreasing productivity under the pessimistic viewpoint. $D M U_{3}$ has the highest productivity progress of 2.975 under the optimistic viewpoint and $D M U_{5}$ the highest productivity decrease of 0.217 . According to the optimistic viewpoint, all DMUs can be ranked by their productivity progress in the order $D M U_{3} \succ D M U_{1} \succ D M U_{4} \succ D M U_{5} \succ D M U_{2}$. However, according to the pessimistic viewpoint, the productivity regress is in the order $D M U_{4} \succ D M U_{1} \succ D M U_{3} \succ D M U_{5} \succ$ $D M U_{2}$. Obviously, the productivity increase ranking may differ from the productivity decrease one.

\section{Conclusions}

Conventional DEA can be used to compute the productivity changes of a DMU over time under the profit MPI model, provided that the input, output, input costs, and output prices are known and exact for each DMU. However, in many situations, some inputs and/or outputs and input-output prices are imprecise. However, the conventional profit MPI model is not suitable to deal with inexact prices. Emrouznejad et al. (2011) studied the overall profit MPI using DEA with imprecise data and proposed two novel methods for measuring overall profit MPI. In this paper, we showed their method has some shortfalls. To overcome these shortfalls, we reformulated the conventional profit MPI model as an IDEA model by incorporating the available information into profit efficiency models and the same information into CR-DEA models in the form of a cone-ratio weight restriction. Additionally, the lower bounds of profit efficiency were easily calculated by solving a linear one-level program. Regarding the upper bounds, we proposes a new approach of solving $n$ linear programming problems for each bound. This is the penalty we pay to calculate the upper bound of the overall profit efficiency when the data are inexact. We also presented a numerical example to demonstrate the applicability of the proposed framework.

Abbreviations

CR-DEA: Cone-ratio DEA; DEA: Data envelopment analysis; DMU: Decision making unit; IDEA: Imprecise DEA; MPI: Malmquist productivity index; UPEA-P: Uncertain profit efficiency of DMU $U_{0}$ in the adjacent period for perfect (all); UPEA-S: Uncertain profit efficiency of $D M U_{0}$ in the adjacent period for some; UPEW-P: Uncertain profit efficiency of $D M U_{0}$ in the within period for perfect; UPEW-S: Uncertain profit efficiency of $D M U_{0}$ in the within-period time for some

Acknowledgments

The author would like to thank the four anonymous reviewers and the editor for their insightful comments and suggestions.

Authors' contributions

The author read and approved the final manuscript.

Funding

This research did not receive any specific grant from funding agencies in the public, commercial, or not-for-profit sectors

Availability of data and materials

Data used in this paper were extracted from Emrouznejad et al., "An overall profit Malmquist productivity index with fuzzy and interval data," Mathematical and Computer Modeling 2011; 54: 2827-2838.

Competing interests

The author declares that he has no competing interests.

Received: 25 April 2019 Accepted: 6 January 2020

Published online: 16 January 2020 


\section{References}

Aghayi N, Tavana M, Maleki B A Malmquist Productivity Index with the Directional Distance Function and Uncertain Data. Sci Iran. In press. https://doi.org/10.24200/sci.2018.5259.1173

Asmild M, Paradi JC, Reese DN, Tam F (2007) Measuring overall efficiency and effectiveness using DEA. Eur J Oper Res 178(1):305-321

Bialas WF, Karwan MH (1984) Two-level linear programming. Manag Sci 30(8):1004-1020

Caves DW, Christensen LR, Diewert WE (1982) The economic theory of index numbers and the measurement of input, output, and productivity. Econometrics 50(6):1393-1414

Caves, DW, Christensen LR, Diewert WE (1982) Multilateral comparisons of output, input, and productivity using superlative index numbers. Econ J 92(365):73-86

Cooper WW, Park KS, YU G (1999) IDEA and AR-IDEA: models for dealing with imprecise data in DEA. Manag Sci 45:597-607

Ebrahimi B, Khalili M (2018) A new integrated AR-IDEA model to find the best DMU in the presence of both weight restrictions and imprecise data. Comput Ind Eng 125:357-363

Emrouznejad A, Rostamy-Malkhalifeh M, Hatami-Marbini A, Tavana M (2011) An overall profit Malmquist productivity index with fuzzy and interval data. Math Comput Model 54:2827-2838

Fang L, Li H (2012) A comment on "cost efficiency in data envelopment analysis with data uncertainty". Eur J Oper Res 220:588-90

Fang, L, Li H (2013) Duality and efficiency computations in the cost efficiency model with price uncertainty. Comput Oper Res 40:594-602

Färe R, Grosskopf S, Lindgren B, Roos P (1992) Productivity change in Swedish pharmacies 1980-1989: A nonparametric Malmquist approach. J Prod Anal 3:85-102

Färe R, Grosskopf S, Norris M, Zhang Z (1994) Productivity growth, technical progress and efficiency change in industrialized countries. Am Econ Rev 84(1):66-83

Farrell MJ (1957) The measurement of productivity efficiency. J R Stat Soc Ser A Gen 120(3):253-281

Fazelabdolabadi B (2019) Uncertainty and energy-sector equity returns in Iran: a Bayesian and quasi-Monte Carlo time-varying analysis. Finan Innov 5(12):1-20

Hatami-Marbini A, Ghelej Beigi Z, Leth Hougaard J, Gholami K (2018) Measurement of Returns-to-Scale using Interval Data Envelopment Analysis Models. Comput Ind Eng 117:94-107

Hatami-Marbini A, Agrell PJ, Fukuyama H, Gholami K, Khoshnevis P (2017) The role of multiplier bounds in fuzzy data envelopment analysis. Ann Oper Res 250(1):249-276

Kou G, Peng Y, Wang G (2014) Evaluation of Clustering Algorithms for Financial Risk Analysis using MCDM Methods. Inf Sci 12:1-12

Lee YK, Park SK, Kima SH (2002) Identification of inefficiencies in an additive model based IDEA (imprecise data envelopment analysis). Comput Oper Res 29:1661-76

Malmquist S (1953) Index numbers and indifference surfaces. Trab Estatistica 4:209-242

Mashayekhi Z, Omrani H (2016) An integrated multi objective Markowitz-DEA cross efficiency model with fuzzy returns for portfolio selection problem. Oper Res 38:1-9

Mostafaee A, Saljooghi FH (2010) Cost efficiency measures in data envelopment analysis with data uncertainty. Eur J Oper Res 202:595-603

Park KS (2001) Duality, efficiency computations and interpretations in imprecise DEA. Eur J Oper Res 131:572-586

Podinovski W (2001) DEA models for the explicit maximization of relative efficiency. Eur J Oper Res 131(1-2):572-576

Tohidi Gh, Razavyan Sh, Tohidnia S (2010) A profit Malmquist productivity index. J Ind Eng Int 6(11):23-30

Tohidi Gh, Razavyan Sh, Tohidnia S (2014) Profit Malmquist Index and Its Global Form in the Presence of the Negative Data in DEA. J Appl Math:1-8. https://doi.org/10.1155/2014/276092

Toloo M, Aghayi N, Rostamy-malkhalifeh M (2008) Measuring overall profit efficiency with interval data. Appl Math Comput 201(1-2):640-649

Vicente LN, Calamai PH (1994) Bilevel and multilevel programming: A bibliography review. J Glob Optim 5(3):291-306

Wanke P, Barros CP, Emrouznejad A (2016) Assessing productive efficiency of banks using integrated Fuzzy-DEA and bootstrapping a case of Mozambican banks. Eur J Oper Res 249(1):378-389

Salehpour S, Aghayi N (2015) The Most Revenue Efficiency with Price Uncertainty. Int J Data Envelopment Anal 3:575-592

Shabani A, Visani F, Barbieri P, Dullaert W, Vigo D (2019) Reliable estimation of suppliers' total cost of ownership: An imprecise data envelopment analysis model with common weights. Omega 78:57-70

Shokouhi AH, Shahriari H, Agrell PJ, Hatami-Marbini A (2014) Consistent and robust ranking in imprecise data envelopment analysis under perturbations of random subsets of data. OR Spectrum 36(1):133-160

Toloo M, Keshavarz E, Hatami-Marbini A (2018) Dual-role factors for imprecise data envelopment analysis. Omega 77:15-31

Ureña R, Kou G, Wu J, Chiclana F, Herrera-Viedma E (2019) Dealing with incomplete information in linguistic group decision making by means of Interval Type-2 Fuzzy Sets. Int J Intell Syst 34(6):1261-1280

Zhang H, Kou G, Peng Y (2019) Soft consensus cost models for group decision making and economic interpretations. Eur J Oper Res 277(3):964-980

\section{Publisher's Note}

Springer Nature remains neutral with regard to jurisdictional claims in published maps and institutional affiliations. 